\title{
El exterminio de la isla de Papayal: etnografías sobre el Estado y la construcción de paz en Colombia
}

Juan Felipe García Arboleda

Bogotá: Editorial Pontificia Universidad Javeriana

2019, 253 páginas

\section{JOHN GIRALDO DÍAZ}

Grupo de Investigación Política y Territorio (Poter),

Universidad Nacional de Colombia, Colombia

DOI: $10.22380 / 2539472 X .1980$

uando leemos El exterminio de la isla de Papayal: etnografías sobre el Estado y la construcción de paz en Colombia, nos convertimos en personas diferentes. A modo de concisa presentación, Michael Taussig resume así los sentipensamientos que desata el libro:

El ojo ve más allá. El Corazón siente más. La mano del escritor se vuelve fuego. Los conceptos se desmoronan y los nuevos paradigmas saltan de entre las cenizas de los viejos. Esto es este libro, y cuando lo leemos, nosotros también, nos encendemos. (21)

El texto de Juan Felipe García equilibra la reflexión teórica y conceptual con el trabajo de campo comprometido y situado; un balance entre la acción y la reflexión, como también lo señala Taussig. La estructura del libro permite pasar de las conceptualizaciones para entender el contexto del estudio de caso en los capítulos 1 y 2 a las nociones para comprender las subjetividades de la población de la isla en los dos capítulos siguientes. Finalmente, el quinto capítulo, lejos de ser un cierre, se convierte en un ejercicio de reflexión profunda del propio autor, 
al cual invita a quien lo siga en su lectura. Con el fin de mostrar mejor esta estructura, resulta necesario detenernos en cada uno de los capítulos.

El primero, de introducción, acude a la ecología política para contextualizar un territorio ubicado al sur del departamento de Bolívar (Colombia), que ante los ajenos es una porción de tierra con vocación productiva, pero para los nativos es una isla cuya vida depende de una intrincada y permanente relación entre lo humano y lo no humano. De allí que el título del libro refiera al exterminio "de la isla” y no “en la isla”. En este sentido, García repasa las principales transformaciones que ha vivido Papayal, tomando como punto de partida los cambios, las continuidades y las interrupciones de sus ciclos vitales. Con estas premisas, basadas en el relacionamiento humano / no humano, una de las primeras conclusiones a las que llega el autor hace evidente la asimetría en esta relación que inclina la balanza no solo hacia lo humano, sino hacia lo humano ajeno al territorio.

Así, en la obra se plantea la antropología como "un saber para revertir la asimetría”, tal como lo sugiere Viveiros de Castro (2013). Adicional a esto, García retoma el concepto de multiplicidad de fenomenologías (Ingold 2000), entendido como la relación entre cuerpo, percepción, imaginación y forma de vida. A partir de esto, propone:

Si nuestro cuerpo y percepción se encuentran tan independizados de las fuentes de vida que provee un espacio, como pasa en la isla de Papayal, va a ser más difícil que podamos imaginarnos ese espacio como un todo vivo, con su sistema circulatorio, con su propio corazón, tal y como los campesinos lo perciben. (66)

En el segundo capítulo se puede observar esta relación asimétrica no como un hecho aislado, sino como un asunto más amplio atendido a través de decisiones y políticas públicas y, más exactamente, a través de instrumentos que racionalizan el actuar estatal sobre los territorios, como la planeación y la tecnopolítica. Tomando como referencia el trabajo de Timothy Mitchell (2002), en el cual se analiza la transición de Egipto hacia la modernidad después de la Segunda Guerra Mundial, García entiende la tecnopolítica como un conjunto de "prácticas y saberes que se autopostulaban como la forma correcta de gobernar una nación” (78), y que en Colombia tomó forma con la llegada de la misión enviada por el Banco Internacional hacia 1949.

La tecnopolítica sería la encargada de ubicar las cuestiones agrarias en el campo del desarrollo productivo, cerrando la puerta a otras racionalidades como las que emergen del pensamiento campesino. Así, el campesino se define como un sujeto racionalizado -y no con racionalidad propia- que forma parte del engranaje productivo. Esto ha permitido, según lo menciona el autor, 
que las soluciones a las problemáticas rurales estén orientadas principalmente a aumentar la productividad del campo.

Además de una necesaria reflexión epistemológica sobre la conceptualización del campesinado, lo agrario y los proyectos de nación, el capítulo aborda los ejercicios de construcción de paz en Colombia con un particular acento en el caso de El Chicoralazo. Este episodio, vivido durante el gobierno de Pastrana Borrero, restó fuerza al sujeto campesino constituido por el agrarismo y representado en la Asociación Nacional de Usuarios Campesinos (ANUC), y permitió que sectores políticos y económicos tomaran control de gran parte de la institucionalidad agraria, resistiéndose así a cambios profundos. El análisis de hechos como este resulta necesario para reflexionar y actuar ante el actual momento de construcción de paz, expresado en la implementación del acuerdo final de paz entre las Fuerzas Armadas Revolucionarias de Colombia - Ejército del Pueblo (FARC-EP) y el Gobierno nacional y en la necesidad de reanudar la mesa de diálogo con el Ejército de Liberación Nacional (ELN). Como conclusión del segundo capítulo, García plantea -basado en el Ensayo sobre el don de Marcel Mauss- que existe una interrupción del circuito de la reciprocidad, pues los campesinos dan sin recibir. Así, se identifican interrupciones en los ciclos vitales de la isla y en los circuitos de reciprocidad con los/as campesinos/as.

El capítulo 3 describe la manera como estas interrupciones y asimetrías afectan la cotidianidad de las personas en la isla de Papayal. Ejemplo de ello es la alteración en el desarrollo de los rituales que acompañan la muerte de una persona de la comunidad, por causa del temor que imprime la violencia paramilitar. García reivindica el oficio etnográfico dotándolo de sensibilidad, profundidad, rigor y respeto; proponiendo un sujeto investigador que llega a detalles de la vida campesina que tocan lo profundo de su ser y que impiden que permanezca inerte. Un sujeto que vive esa transformación dialéctica generada por la inmersión en campo y que vuelve inútil cualquier búsqueda de neutralidad valorativa.

A través de este ejercicio etnográfico, se puede identificar una nueva interrupción, esta vez en la reciprocidad intergeneracional para la construcción de una vida digna en el territorio. Mientras la primera generación de campesinos/as de la isla mantiene viva la esperanza del retorno de la justicia y la llegada de un nuevo tiempo mesiánico que - en palabras de García-recomponga las relaciones y restablezca las simetrías, las generaciones posteriores apelan a la venganza, al desarraigo, al abandono e incluso al mismo uso de la violencia que ha causado esas interrupciones y asimetrías.

Los dos últimos capítulos de este trabajo tienen la característica de aportar a la construcción de la paz en el país. En el capítulo 4 se construye un relato del surgimiento, la consolidación y la disputa de fuerzas irregulares y regulares en 
la isla de Papayal y el papel desempeñado por los gobiernos de turno. Principalmente, se recurre a testimonios y declaraciones de víctimas y victimarios del paramilitarismo que se suman a la imperiosa tarea de robustecer el sistema de justicia transicional; una tarea en la cual la antropología - como lo demuestra el libro- puede desempeñar un rol destacado.

Aunque las contradicciones no estén del todo resueltas en la isla, el último capítulo presenta una especie de canto de esperanza entonado por la comunidad, en el cual se afirma la importancia del trabajo colectivo y los liderazgos para hacer frente a las injusticias expresadas en determinados actos de habla estatales. Se podría concluir en esta sección que la esperanza se aviva cuando la organización comunitaria se hace más fuerte.

En este ir y venir de la isla, a lo largo de los cinco capítulos, son diversas las personas que se conocen y diversas las reflexiones a las que se llega. Uno de los personajes que resulta más interesante, aunque es escasamente mencionado en el libro, es el Monchi Pavero, un cantante oriundo de la isla preocupado por el bienestar de su gente campesina. Siguiendo el rastro del Monchi, nos encontramos con una publicación del Centro Nacional de Memoria Histórica de la cual hizo parte: Tocó cantar, significativo título en el que ese verbo conjugado a la colombiana advierte que, ante la pasividad y la resignación, es necesario actuar. Un verbo imperativo que llena de esperanza y resistencia el sentipensar de las comunidades.

Del Monchi Pavero se encuentran algunos videos en YouTube, todos grabados con un celular y con un fondo lleno de cotidianidad cienaguera: un hombre que va avanzando con su chalupa entre inundaciones; nombrando al ganado y en faenas de ordeño; cantando versos que señalan su identidad, el arraigo y la causa de su desdicha, pero también la esperanza de un mejor futuro que, como en otras ocasiones y culturas, se le encomienda a Dios. En las canciones del Monchi, entonces, también se anhela ese tiempo mesiánico.

En cuanto a las reflexiones que deja este recorrido por la isla, puede resaltarse el trasfondo de este libro: el diálogo entre la antropología y el derecho. García es doctor en antropología y sus bases de formación están en el derecho. Es en el ejercicio del derecho como conoce la isla de Papayal y, junto a su comunidad, decide emprender pugnas jurídicas contra fuerzas desbordantes. Pero el conocimiento del sistema jurídico, la argumentación ante las Altas Cortes, el análisis de la jurisprudencia o la identificación de los casos en los que la fuerza pública extralimita su actuar serían insuficientes sin el reconocimiento de aquellos recursos culturales que las comunidades tienen para proteger la vida misma; es decir, sin una antropología de la ley, necesaria para la construcción de la paz, que defienda la vida en sus múltiples expresiones, incluyendo la vida no humana. 
Finalmente, El exterminio de la isla de Papayal reafirma al campesinado como un sujeto cultural y de derechos que puede ayudar a reactivar y mantener los ciclos vitales de los territorios y superar las asimetrías impuestas por la violencia. Es allí donde el libro resulta necesario pues no solo identifica estas interrupciones y asimetrías, sino que les reconoce a los/as campesinos/as su actuar transformador.

Aunque la aproximación ontológica propuesta por García genera insumos para definir al campesinado en relación con su entorno como un sujeto de derechos, esto presenta limitaciones para ampliar este enfoque de derechos a aquello no humano, es decir, a la isla en su conjunto. En este sentido, Bruno Latour (2008), quien retoma ideas centrales del pensamiento de Gabriel Tarde, se interesa por aquellas redes que se configuran con la asociación entre lo humano y lo no humano y en las cuales las mediaciones son el factor constituyente. De esta teoría del actor-red de Latour resultan aportes valiosos para comprender la isla no como un organismo vivo desde la perspectiva humana, sino como una asociación viva gracias a la relación entre lo humano y lo no humano. Así, la isla de Papayal se convierte en sujeto de derechos frente al cual las actuaciones del Estado no pueden orientarse exclusivamente a resolver la relación de propiedad sobre la tierra, pues, como se ve a lo largo del libro, se trata de una relación que puede ser fácilmente alterada por actores armados legales o ilegales.

\section{Referencias}

Ingold, Tim. 2000. The perception of the environment: essays on livelihood, dwelling and skill. Nueva York: Routledge.

Latour, Bruno. 2008. Reensamblar lo social: una introducción a la teoría del actor-red. Buenos Aires: Manantial.

Mitchell, Timothy. 2002. Rule of experts: Egypt, techno-politics, modernity. Los Ángeles: University of California Press.

Viveiros de Castro, Eduardo. 2013. La mirada del jaguar: introducción al perspectivismo amerindio. Entrevistas. Buenos Aires: Tinta Limón. 